\title{
ELECTROSPINNING OF NIOBIUM-TUNGSTEN OXIDE NANOFIBRES
}

\author{
Oluwagbenga Fatile ${ }^{1 \underline{a}}$, Martin Pugh $^{1 \underline{b}}$, Mamoun Medraj ${ }^{1 \underline{c}}$ \\ ${ }^{1}$ Department of Mechanical, Industrial and Aerospace Engineering, Concordia University, Montreal, Canada ${ }^{a}$ \\ *a oluwagbenga.fatile@mail.concordia.ca, ${ }^{\mathrm{b}}$ pugh@encs.concordia.ca ${ }^{\mathrm{c} m m e d r a j @ e n c s . c o n c o r d i a . c a}$
}

\begin{abstract}
Recently, there is a growing interest in niobium-tungsten oxide nanowires. This material had been reported to possess unique features such as open cavities for storing lithium ions, significant structural stability, and high power density. These deemed this material a very promising electrode candidate for lithium-ion batteries. Over the last few decades, electrospinning has become the most widely used technique for fabricating nanowires due to its low cost, simplicity, high yield, tunable porosity, high surface-tovolume ratio, control over various process parameters, and ability to control the composition of the nanofibers. More interestingly, it is possible to carry out heat treatments on the electrospun nanofibers in order to remove the associated polymer and convert them to nanowires. Also, heat treatments are necessary to improve the surface structure and crystallinity of materials for the Li-ion battery' electrodes. Heat treatments also lead to the creation of longer mean paths for the free electrons which had been reported to enhance electrical conductivity of materials. Previous investigations carried out on niobium-tungsten nanowires show that the material can be annealed at either $930^{\circ} \mathrm{C}$ or $1000^{\circ} \mathrm{C}$. However, the effect of annealing temperature on the diameter and crystallite size of niobium-tungsten oxide nanowires has not yet been established. Hence, this current study focuses on the fabrication and thermal study of niobium-tungsten oxide nanowires annealed at different temperatures $\left(850^{\circ} \mathrm{C}, 900^{\circ} \mathrm{C}, 950^{\circ} \mathrm{C}, 1000^{\circ} \mathrm{C}\right.$, and $\left.1050^{\circ} \mathrm{C}\right)$ for 8 hours. The structure and morphology of the samples were investigated using X-ray diffraction XRD), Scanning Electron Microscope (SEM) and Energy Dispersive Spectrometer (EDS). All the diffraction peaks obtained from the XRD can be well indexed to the tetragonal structure phase without traces of extra phases. The results obtained from EDS analysis confirm that the nanowires are composed of tungsten, niobium, and oxygen only. Furthermore, the crystallite size generally increases progressively with increasing annealing temperature; the nanowires annealed at $850^{\circ} \mathrm{C}, 900^{\circ} \mathrm{C}, 950^{\circ} \mathrm{C}, 1000^{\circ} \mathrm{C}$, and $1050^{\circ} \mathrm{C}$ exhibited the crystallite size of $64.94,67.41,70.10,75.15$, and $75.06 \mathrm{~nm}$, respectively. The SEM results also reveal that the average diameter of the nanowires decreases with increasing annealing temperature. In addition, the SEM images show that the nanowires appear to be formed by interconnected particles or crystals. According to the very recent literature, the niobium-tungsten nanowires have potential applications in Li-ion batteries, photocatalyst, and gas sensing devices.
\end{abstract}

